Short Communication

\title{
Preparation of Pd-Co Bimetallic Nanoparticles Supported on Graphene for Rapid Electrochemical Detection of Nitrite
}

\author{
Jinlan Jiang*, Shijian Bao, Jun Lv, Xinping Yu \\ School of Intelligent Manufacturing, Zhejiang Guangsha Vocational and Technical University of \\ Construction, Dongyang, Zhejiang, 322100, P.R. China \\ *E-mail: jinlanjiang2018@163.com
}

Received: 5 September 2021 / Accepted: 26 October 2021 / Published: 6 December 2021

\begin{abstract}
Nitrite has been widely used in industrial and agricultural production and commonly exists in food, drinking water, organisms and the environment. However, nitrite is a toxic contaminant that can be very harmful to humans. In recent years, various methods for detecting nitrite have been developed, among which electrochemical methods are favored for their simplicity, rapidity, sensitivity and low price. In this paper, a graphene supported nano-PdCo alloy catalyst is proposed for the preparation of electrochemical nitrite sensor. The results show that the as-prepared sensor has a good electrocatalytic effect on the detection of nitrite. The electrochemical sensor can be adopted for rapid detection of nitrite with a wide range of $20 \sim 1050 \mu \mathrm{M}$ and the low detection limit of $7.7 \mathrm{nM}$. The proposed sensor has been successfully applied to the detection of nitrite in pure water, with the recovery rate being $99.17 \%$ to $107.24 \%$, which indicates that the sensor has good stability and reproducibility.
\end{abstract}

Keywords: Bimetallic Nanoparticle, Electrochemical sensor; Nitrite; Graphene; Nanocatalysts

\section{$\underline{\text { FULL TEXT }}$}

(C) 2022 The Authors. Published by ESG (www.electrochemsci.org). This article is an open access article distributed under the terms and conditions of the Creative Commons Attribution license (http://creativecommons.org/licenses/by/4.0/). 